\title{
Evaluation of the Effects of Triple PGPR Isolates and Biological Fertilizer Formulations Formed with Different Carriers on Growth Parameters in Pazar-20 Tea Clone
}

\author{
Yaşar ERTÜRK ${ }^{1 a *}$ Ramazan ÇAKMAKÇI ${ }^{2 b}$ Meral KUTLU $^{3 c}$ Hakan KELES $^{4 d}$ \\ ${ }^{1}$ Kırşehir Ahi Evran Üniversitesi Ziraat Fakültesi Bahçe Bitkileri Bölümü Kırşehir, TÜRKIYE \\ ${ }^{2}$ Çanakkale 18 Mart Üniversitesi Ziraat Fakültesi Tarla Bitkileri Bölümü Çanakkale, TÜRKIYYE \\ ${ }^{3}$ Atatürk Üniversitesi Ziraat Fakültesi Tarla Bitkileri Bölümü Erzurum, TÜRKIYE \\ ${ }^{4}$ Yozgat Bozok Üniversitesi Ziraat Fakültesi Bahçe Bitkileri Bölümü Yozgat, TÜRKIYYE \\ ahttps://orcid.org/0000-0003-2525-0260, ${ }^{b}$ https://orcid.org/0000-0002-1354-1995 \\ chttps://orcid.org/0000-0002-3288-1266, ${ }^{d}$ https://orcid.org/0000-0002-8225-931X
}

*Sorumlu yazar: yasar.erturk@ ahievran.edu.tr

\section{A B S T R A C T}

This study was established with two-years-old tea seedlings in the Pazar-20 tea clone in pots and eight applications as five different biological fertilizers, triple bacteria combinations (F1, F2, F3, F4 and, F5), one biological fertilizer, NPK fertilization (1400 mg compound 25:5:10/seedling) and control (fertilizer and bacteria not applied) applications, seven carriers as one liquid six solid. It was established with four replications and five seedlings in each replication according to the factorial arrangement (8 applications $\mathrm{x} 7$ carriers) with different carriers. For preliminary evaluations, only plant height, stem diameter and, number of leaves were evaluated without cutting the seedlings. In the experiment, at the end of November 2013, and 2014, seedlings were harvested from equal height, branch+leaf weight, fresh and dry leaf yield, chlorophyll content (SPAD value), and leaf area results were evaluated. Depending on the bacterial inoculations, fertilizer applications, and the carriers used, the inoculated bacterial formulations, fertilizer applications, and carriers significantly affected the stem diameter, plant height, leaf number, branch+leaf weight, fresh and dry leaf weight, chlorophyll content of tea seedlings. According to the carrier averages, mineral fertilization, F1, F2, F5, and biological fertilizer applications, which caused a significant increase in stem diameter, plant height, number of leaves, and chlorophyll content compared to the control, were in the same group. All the selected combinations increased fresh and dry leaf weight compared to the control, and the increasing rates were statistically significant $(\mathrm{p} \leq 0.05)$. According to the average fertilizer application, the liquid carrier gave the most relevant result in terms of measured parameters, followed by solid leonardite, compost, and peat-based carriers, respectively.

\section{ARTICLE INFO}

Research article

Received: 13.07.2021

Accepted: 23.09.2021

Keywords:

Camellia sinensis L, PGPR, Vegetative

Growth, Chlorophyll content (SPAD)

To Cite: $\quad$ Ertürk Y, Çakmakcı R, Kutlu M, Keles H 2021. Evaluation of the Effects of Triple PGPR Isolates and Biological Fertilizer Formulations Formed with Different Carriers on Growth and Development Parameters in Pazar-20 Tea Clone, MJAVL Sciences. 11 (2) 109-119 


\section{INTRODUCTION}

Tea (Camellia sinensis L.), a cultivated evergreen plant, is native to China, later spread to India and Japan, then to Europe and Russia, arriving in the New World in the late $17^{\text {th }}$ century. Green, oolong, and black tea are all made from the same plant species, $C$. sinensis L. but differing in their appearance, organoleptic taste, chemical content as well as flavor due to their respective fermentation process. The chemical components of tea leaves include polyphenols (catechins and flavonoids), alkaloids (caffeine, theobromine, theophylline, etc.), volatile oils, polysaccharides, amino acids, lipids, vitamins (e.g., vitamin C), inorganic elements (e.g., aluminum, fluorine, and manganese), etc. Tea (Camellia sinensis), which has such valuable nutritional content, is grown in many subtropical and tropical regions. Today has great popularity among other beverages worldwide (Sharangi 2009; Amutha et al. 2010; Kacar 2010).

The tea plant is a species that needs high amounts of micro and macronutrients, especially $\mathrm{N}, \mathrm{P}, \mathrm{K}$, and $\mathrm{Mg}$ for its growth (Verma 1997; Wanyoko et al. 1997). Nutrients provided by inorganic fertilizers at rates between $150 \mathrm{~kg}$ and $300 \mathrm{~kg} \mathrm{~N} / \mathrm{ha}$ are required for commercial tea production (black tea-fermented tea). Also, it was confirmed that tea yield increased significantly with increasing $\mathrm{N}$ and $\mathrm{K}$ levels up to a point. While $\mathrm{N}$ has the highest content in the stems of the tea plant, this element is followed by $\mathrm{K}, \mathrm{Ca}, \mathrm{P}, \mathrm{S}, \mathrm{Mg}$, and $\mathrm{Zn}$, respectively. In particular, nitrogen plays a vital role in the physiology of the tea plant (Kacar 2010; Verma 1997). However, although high amounts of N used for production increase tea yield to a certain level, high levels of $\mathrm{N}$ contents accumulated in the leaves may adversely affect the quality of the grown product. Indeed, the quality of tea depends on the organic and inorganic composition of the harvested leaves. These are responsible for the taste, aroma, and color of the tea. In this context, balanced nutrition of the tea plant is essential as a prerequisite for high-quality tea (Verma 1997; Wanyoko et al. 1997; Kacar 2010; Gebrewold 2018).

It has been reported in many studies that tea production, which has been carried out with inorganic nutrients until now, causes severe problems in soil fertility, tea leaf quality, and its effects on the environment. Many researchers state that the agricultural chemicals used can't sustain production increases, can't restore soil fertility, and new alternatives should be focused on restoring the natural biological-chemical and physical properties of the soil (Islam et al. 2015; Islam et al. 2017). Furthermore, intensive use of inorganic fertilizers leads to deterioration of the cation exchange capacity (CEC) and clay structure of the soil, high Al and silicate concentrations in the drainage water, and nitrogen gas emissions, air pollution, and deterioration of underground water resources. Today, adopting organic or sustainable agricultural principles can create a different perspective to reduce these problems, which are the result of conventional farming, and to re-establish the natural balance (Verma 1997; Wanyoko et al. 1997).

Many practices such as taking integrated control methods as a basis in sustainable agricultural activities, increasing the amount of soil organic matter by expanding the use of organic fertilizers, and increasing the diversity and activities of microorganisms are prioritized (Phukan et al. 2012; Nepolean et al. 2021). The aim of having an environmentally friendly plantation that aims to protect the ecology and natural habitat without polluting the soil, air, and water, while focusing on sustainable cultivation, is the basis of this philosophy. One of the applications used to achieve these purposes is the application of plant growth-promoting bacteria (PGPB).

Promoting plant growth with plant growth-promoting bacteria is gaining more and more attention worldwide, especially in reducing the need for chemical fertilizer use. At the same time, the fact that they are environmentally friendly, low-cost, and easy-to-use products encourage their more intensive use. Therefore, studies were started on the use of beneficial bacteria for agricultural purposes, first on annual vegetable species. Then it was determined that these bacteria increased plant growth, yield in apple, cherry, citrus fruits, blueberry, mulberry, kiwi, and strawberry, and rooting in cuttings (Kloepper 1994; Sudhakar et al. 2000; Glick 1995; Prrlak et al. 2007; Çakmakçı et al. 2010; Ertürk et al. 2008; 2010b; 2011a; 2011b; 2012). However, research on using this technology for a perennial herb such as tea (Camellia sinensis L.O. Kuntze) has been relatively limited. In our country, studies on the isolation, identification, and characterization of biological fertilizer candidate(s) from tea plantations and their trials both in pots and in field conditions were continuing in the studies initiated in 2007 with the support of TUBITAK to obtain biological fertilizer formulations in tea cultivation. Many bacterial isolates identified in this context have been studied in biological fertilizer formulations as single, double or multiple with different formulations and carriers (Çakmakçı et al. 2010; 2012; 2017; Ertürk et al. 2010a; 2011c; 2013; 2014; Çakmakç1 2019). Within the scope of this study, the effects of bio formulations prepared with three bacterial isolates using different carriers on yield and some growth components of young tea plants (Pazar $20 \mathrm{cv}$.) with different carriers were tried to be determined.

\section{MATERIALS AND METHOD}

This study was established in pots with 2-years-old seedlings of the Pazar $20 \mathrm{cv}$. In the experiment, a total of eight applications, including 12 different biological fertilizers, triple bacteria combination, one biological fertilizer, standard NPK fertilization (1400 mg compound 25:5:10/seedling), and control (without fertilizer and bacteria). It was planned 
to have four replications and five seedlings in each replication according to the factorial arrangement (8 applications $\mathrm{x}$ 7 carriers) with seven different carriers, as solid. In addition, this study was carried out in 2013 and 2014 . The characteristics of the isolates and carriers used in this experiment are given in Table 1 and Table 2.

Table 1. Some characteristics of bacteria in the combinations used in the experiment with two-years-old seedlings in the Pazar-20 tea clone

\begin{tabular}{|c|c|c|c|c|c|c|c|c|}
\hline Strain No & MIS Diagnostic Result & Comb. & OK test & $\begin{array}{c}\text { CAT } \\
\text { test }\end{array}$ & $\begin{array}{l}\mathrm{N} \\
\text { fixation }\end{array}$ & $\begin{array}{c}\text { Sucrose } \\
\text { test }\end{array}$ & $\begin{array}{c}\text { Phosphate } \\
\text { Solubilizat } \\
\text { ion }\end{array}$ & $\mathrm{ACCD}$ \\
\hline RC11 & Bacillus atrophaeus & F1 & $\mathrm{Z}+$ & $\mathrm{K}+$ & + & + & + & 2 \\
\hline $\mathrm{RC} 07$ & Bacillus megaterium & & $\mathrm{Z}+$ & $\mathrm{K}+$ & + & - & $\mathrm{K}+$ & TY \\
\hline $\mathrm{RC} 77$ & Pseudomonas fluorescens & & $\mathrm{K}+$ & + & $Z_{+}$ & - & + & 2 \\
\hline RC63 & Bacillus subtilis & $\mathrm{F} 2$ & + & $\mathrm{K}+$ & $\mathrm{K}+$ & - & $\mathrm{Z+}$ & 3 \\
\hline $21 / 3$ & Bacillus megaterium & & - & + & $\mathrm{K}+$ & - & $\mathrm{K}+$ & 2 \\
\hline $8 / 4$ & Pseudomonas fluorescens & & $\mathrm{K}+$ & $\mathrm{Z}+$ & + & $\mathrm{K}+$ & + & 3 \\
\hline $36 / 10$ & Bacillus subtilis & F3 & - & $\mathrm{K}+$ & $\mathrm{K}+$ & + & + & 6 \\
\hline $42 / 2$ & Bacillus megaterium & & - & + & + & - & + & TY \\
\hline $8 / 6$ & Pseudomonas fluorescens & & $\mathrm{K}+$ & $\mathrm{K}+$ & + & $\mathrm{Z}+$ & $\mathrm{K}+$ & 2 \\
\hline $39 / 3$ & Bacillus subtilis, & $\mathrm{F} 4$ & Z+ & $\mathrm{K}+$ & $\mathrm{K}+$ & + & Z+ & 4 \\
\hline $42 / 4$ & Bacillus megaterium & & - & + & $\mathrm{K}+$ & - & + & 8 \\
\hline $9 / 7$ & Pseudomonas fluorescens & & + & + & $\mathrm{K}+$ & $\mathrm{K}+$ & + & 2 \\
\hline RC521 & Bacillus subtilis & F5 & - & $\mathrm{K}+$ & $\mathrm{K}+$ & + & - & 3 \\
\hline $42 / 4$ & Bacillus megaterium & & - & + & $\mathrm{K}+$ & - & + & 8 \\
\hline $9 / 7$ & Pseudomonas fluorescens & & + & + & $\mathrm{K}+$ & $\mathrm{K}+$ & + & 2 \\
\hline
\end{tabular}

OK: oxidase; CAT: catalase; ACC: aminocyclopropane carboxylate deaminase activity (two strong positives, eight weak positives); TY: not tested; +: positive, K+: strongly positive; Z+: weak positive

Table 2. Carrier formulas used in the experiment and some of their components

\begin{tabular}{ccll}
\hline Carrier No & $\begin{array}{c}\text { Carrier } \\
\text { Code }\end{array}$ & \multicolumn{1}{c}{ Carrier Name } & \multicolumn{1}{c}{ Carrier Content } \\
\hline 1 & $\mathrm{~K}$ & Tea compost-based carrier & compost, animal manure, clampe etc. \\
2 & $\mathrm{~T}$ & Solid peat-based carrier & peat, glycerol, etc. \\
3 & $\mathrm{P}$ & Solid perlite-based carrier & perlite, peat, clamp, glycerol, etc. \\
4 & $\mathrm{~L}$ & Solid leonardite-based carrier & leonardite, clamp etc. \\
5 & $\mathrm{Z}$ & Solid zeolite-based carrier & zeolite, vermiculite, clamp, etc. \\
6 & $\mathrm{~V}$ & Solid vermiculite based carrier & vermiculite, clamp, etc. \\
7 & $\mathrm{~S}$ & Liquid-based organic carrier & whey, seaweed, grass juice, etc. \\
\hline
\end{tabular}

Morphometric parameters and chlorophyll analysis were carried out at the end of each growth period (end of November, beginning of December). Morphometric parameters such as the diameter of the stem (digital caliper-mm), the height of plant (tape measure-cm), fresh leaves+shoots weight, leaf area (SPAD-502, Konica Minolta Sensing, Inc. Japan- $\mathrm{cm}^{2}$ ), fresh leaves weight $(\mathrm{g})$, dry weight of leaves $(\mathrm{g})$ were documented adopting standard procedures. The Excel 2010 and SPSS 20 were used for data analysis, and the LSD multiple comparison method was to conduct the significant test. These data were presented in Table 3 and shown in Figure 1.

\section{RESULTS AND DISCUSSION}

In this experiment, only plant height, stem diameter, and the number of leaves were evaluated without cutting the seedlings for preliminary evaluations. In all of these and other pot experiments, seedlings were harvested by cutting from equal height in November 2013, branch+leaf weight and fresh and dry leaf yield, chlorophyll content (SPAD value), and leaf area results were evaluated (Table 3).

Depending on the inoculated bacteria, fertilizer applications, and carriers used, inoculated formulations, fertilizer applications, and carriers caused significant increases in stem diameter, plant height, leaf number, branch+leaf weight, 
fresh and dry leaf weight, chlorophyll content in tea seedlings. Mineral fertilization and F1, F2, F5 carriers and biological fertilizer applications, which caused a significant increase in stem diameter, plant height, number of leaves, and chlorophyll content compared to the control, were in the same group according to the carrier averages.

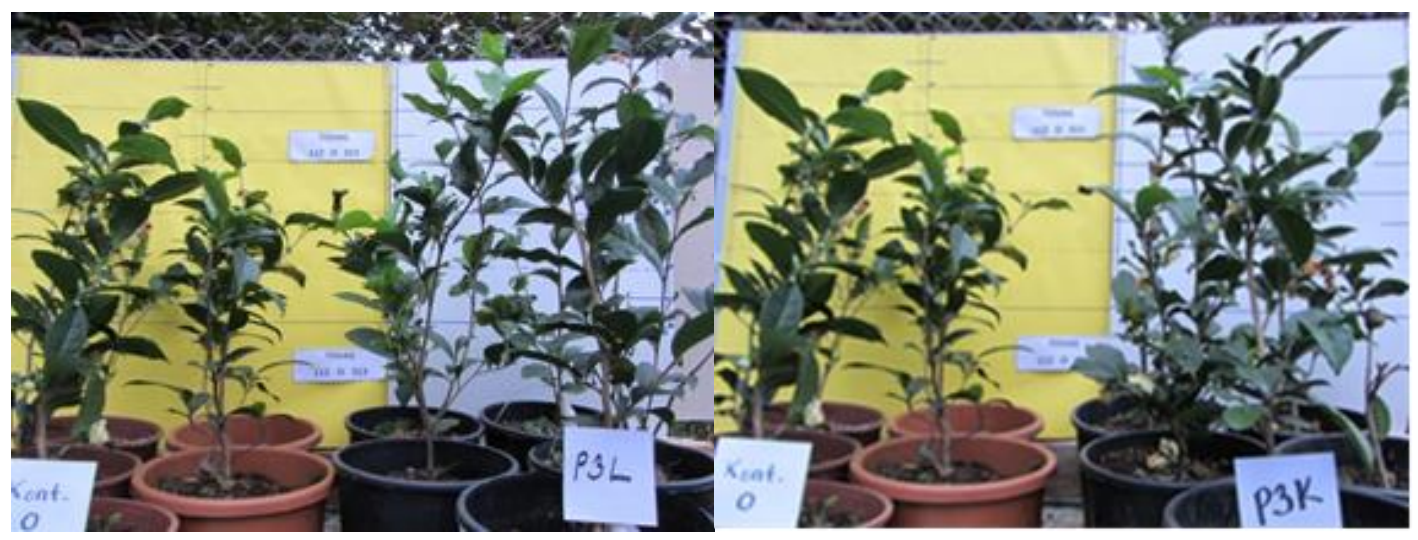

Figure 1. Compared to control (left); seedlings treated with $\mathrm{F} 3 \mathrm{x}$ compost on the right and F3 $\mathrm{x}$ leonardite on the left (end of 1st year)

All of the selected combinations increased the fresh and dry leaf weight compared to the control, and the increasing rates were found to be statistically significant $(p \leq 0.05)$. F4, F5, F3 carriers, which showed high efficiency in terms of fresh leaf weight, caused a considerable increase in total biomass compared to biological fertilizer and mineral fertilizer application. The most suitable carrier in terms of dry leaf weight gave formulas F3 and F5, which are more effective than mineral fertilization. According to the average fertilizer application, the liquid carrier gave the most relevant result in terms of measured parameters, followed by solid leonardite, compost, and peat-based carriers, respectively (Table 3).

It has been determined that the compost-based carrier obtained from tea wastes stands out especially in terms of dry leaf weight and chlorophyll content. However, in terms of the parameters discussed, it was determined that the efficiency of the perlite-based solid carrier was low. In terms of the evaluated parameters, in general, in all formulations and fertilizer applications, perlite and zeolite-based carriers gave the weakest results. In contrast, the most suitable values in terms of branch+leaf, fresh and dry leaf weight were obtained from compost and leonardite-based carriers and F4 and F5 formulations (Table 3).

Leaf chlorophyll (SPAD) and leaf area values are critical criteria for healthy growth and development for the tea plant, which is a type of fruit whose leaves are used. All of the applied formulations caused significant increases in both SPAD and leaf area values compared to the control, and the difference between the averages of these applications was found to be statistically significant. Among the formulations, F3 and F4 applications created the highest values in terms of these parameters, and a similar distribution was formed in terms of carriers (Table 3).

Table 3. The effects of the different carrier, bacterial combinations, and mineral fertilizer application on yield and growth parameters in Pazar-20 tea clone (2013).

\begin{tabular}{|c|c|c|c|c|c|c|c|c|}
\hline Treat & : & $\begin{array}{c}\text { Trunk } \\
\text { Diameter } \\
(\mathrm{mm})^{* *}\end{array}$ & $\begin{array}{l}\text { Heigth of } \\
\text { Plant } \\
(\mathrm{cm})\end{array}$ & $\begin{array}{c}\text { Fresh } \\
\text { Leaves+Shoots } \\
\text { (g/seedling) }\end{array}$ & $\begin{array}{l}\text { Fresh Leaf } \\
\text { Weigth } \\
\text { (g/seedling) }\end{array}$ & $\begin{array}{l}\text { Dry Leaf } \\
\text { Weigth } \\
\text { g/seedling }\end{array}$ & $\begin{array}{l}\text { Clorophyl } \\
\text { (SPAD) } \\
\text { Content }\end{array}$ & $\begin{array}{l}\text { Leaf } \\
\text { Area } \\
\left(\mathrm{cm}^{2}\right)\end{array}$ \\
\hline \multirow[t]{8}{*}{ Cont } & $\mathrm{K}$ & $6.91 \mathrm{f}-\mathrm{i}$ & 47.74 n-o & 24.311 & $17.29 \mathrm{~lm}$ & $9.13 \mathrm{k}-\mathrm{m}$ & 75.45 a-e & $23.3 \mathrm{i}-1$ \\
\hline & $\mathrm{T}$ & $7.08 \mathrm{~d}-\mathrm{i}$ & 48.221 -о & 25.991 & $17.68 \mathrm{kl}$ & $9.47 \mathrm{kl}$ & $65.54 \mathrm{e}-\mathrm{g}$ & $23.2 \mathrm{i}-1$ \\
\hline & $\mathrm{P}$ & $5.86 \mathrm{j}$ & 45.09 o & 24.031 & $15.87 \mathrm{~m}$ & $8.58 \mathrm{~m}$ & $56.98 \mathrm{~g}$ & 20.21 \\
\hline & $\mathrm{L}$ & $7.02 \mathrm{e}-\mathrm{i}$ & $48.80 \mathrm{k}-\mathrm{o}$ & 25.341 & $15.96 \mathrm{~m}$ & $8.65 \mathrm{~m}$ & $59.17 \mathrm{~g}$ & 20.91 \\
\hline & $\mathrm{Z}$ & $6.74 \mathrm{hi}$ & $48.211-\mathrm{o}$ & 25.761 & $15.89 \mathrm{~m}$ & $8.58 \mathrm{~m}$ & $56.94 \mathrm{~g}$ & 19.91 \\
\hline & V & $6.61 \mathrm{i}$ & $47.93 \mathrm{~m}-\mathrm{o}$ & 25.431 & $16.20 \mathrm{~m}$ & $9.06 \mathrm{~lm}$ & $61.96 \mathrm{fg}$ & $22.0 \mathrm{kl}$ \\
\hline & $\mathrm{S}$ & $7.17 \mathrm{c}-\mathrm{i}$ & 52.74 i-n & 24.431 & $16.20 \mathrm{~m}$ & $8.55 \mathrm{~m}$ & $58.92 \mathrm{~g}$ & 20.91 \\
\hline & Average & $6.77 \mathrm{~b}$ & 48.39 c & $25.04 \mathrm{f}$ & $16.44 \mathrm{~d}$ & $8.86 \mathrm{f}$ & $62.14 \mathrm{c}$ & $21.48 \mathrm{c}$ \\
\hline \multirow[t]{2}{*}{ NPK } & $\mathrm{K}$ & $8.07 \mathrm{ab}$ & $57.74 a-j$ & $33.35 \mathrm{f}-\mathrm{h}$ & $21.25 \mathrm{~g}-\mathrm{i}$ & $11.82 \mathrm{e}-\mathrm{g}$ & $80.76 \mathrm{ab}$ & $32.2 \mathrm{a}-\mathrm{c}$ \\
\hline & $\mathrm{T}$ & $8.20 \mathrm{ab}$ & $58.31 \mathrm{a}-\mathrm{j}$ & $31.92 \mathrm{~g}-\mathrm{j}$ & $20.47 \mathrm{hi}$ & $11.07 \mathrm{~g}-\mathrm{i}$ & $76.24 \mathrm{a}-\mathrm{e}$ & $27.0 \mathrm{~d}-\mathrm{j}$ \\
\hline
\end{tabular}


Ertürk et al. / Manas Journal of Agriculture Veterinary and Life Sciences 11 (2) (2021) 109-119

\begin{tabular}{|c|c|c|c|c|c|c|c|c|}
\hline & $\mathrm{P}$ & $7.02 \mathrm{e}-\mathrm{i}$ & $54.85 \mathrm{~d}-\mathrm{j}$ & $28.80 \mathrm{k}$ & $18.38 \mathrm{kl}$ & $9.85 \mathrm{j}-1$ & $68.13 \mathrm{c}-\mathrm{g}$ & 24.0 h-1 \\
\hline & $\mathrm{L}$ & $8.13 \mathrm{ab}$ & $61.25 \mathrm{a}-\mathrm{c}$ & $30.12 \mathrm{j}-\mathrm{k}$ & $19.94 \mathrm{ij}$ & $10.42 \mathrm{ij}$ & 74.64 a-e & $26.2 \mathrm{e}-\mathrm{j}$ \\
\hline & $\mathrm{Z}$ & 7.73 a-e & $60.28 \mathrm{a}-\mathrm{f}$ & $30.65 \mathrm{i}-\mathrm{k}$ & $19.87 \mathrm{ij}$ & $10.79 \mathrm{hi}$ & 73.65 a-e & $26.1 \mathrm{e}-\mathrm{j}$ \\
\hline & V & $7.58 \mathrm{a}-\mathrm{g}$ & $57.96 \mathrm{a}-\mathrm{j}$ & $33.88 \mathrm{e}-\mathrm{g}$ & $21.69 \mathrm{f}-\mathrm{h}$ & $11.52 \mathrm{f}-\mathrm{h}$ & $80.40 \mathrm{a}-\mathrm{c}$ & $28.5 \mathrm{~b}-\mathrm{g}$ \\
\hline & $\mathrm{S}$ & $8.21 \mathrm{ab}$ & $63.78 \mathrm{a}$ & $35.71 \mathrm{c}-\mathrm{e}$ & $22.33 \mathrm{e}-\mathrm{g}$ & $11.37 \mathrm{f}-\mathrm{h}$ & $82.77 \mathrm{a}$ & $29.3 \mathrm{~b}-\mathrm{g}$ \\
\hline & Average & $7.85 \mathrm{a}$ & 59.17 a & 32.06 c-e & 20.56 b & $10.98 \mathrm{de}$ & $76.65 \mathrm{ab}$ & $27.63 \mathrm{ab}$ \\
\hline \multirow[t]{8}{*}{ F1 } & $\mathrm{K}$ & $7.97 \mathrm{ab}$ & $54.28 \mathrm{e}-\mathrm{k}$ & $33.70 \mathrm{e}-\mathrm{g}$ & $21.16 \mathrm{~g}-\mathrm{i}$ & $11.55 \mathrm{f}-\mathrm{h}$ & 77.37 a-e & $26.7 \mathrm{~d}-\mathrm{j}$ \\
\hline & $\mathrm{T}$ & $7.90 \mathrm{a}-\mathrm{c}$ & $58.13 \mathrm{a}-\mathrm{j}$ & $28.56 \mathrm{k}$ & $17.94 \mathrm{kl}$ & $10.73 \mathrm{hi}$ & $76.53 \mathrm{a}-\mathrm{e}$ & $25.2 \mathrm{~g}-\mathrm{k}$ \\
\hline & $\mathrm{P}$ & $6.73 \mathrm{hi}$ & $53.10 \mathrm{i}-\mathrm{n}$ & 24.901 & $15.99 \mathrm{~m}$ & $9.70 \mathrm{j}-1$ & $61.82 \mathrm{fg}$ & $23.0 \mathrm{j}-1$ \\
\hline & $\mathrm{L}$ & $8.31 \mathrm{a}$ & $58.83 \mathrm{a}-\mathrm{i}$ & $30.59 \mathrm{i}-\mathrm{k}$ & $18.75 \mathrm{jk}$ & $10.32 \mathrm{ij}$ & $79.53 \mathrm{a}-\mathrm{d}$ & $27.9 \mathrm{c}-\mathrm{h}$ \\
\hline & $\mathrm{Z}$ & 7.75 a-e & $62.08 \mathrm{a}-\mathrm{c}$ & $32.30 \mathrm{~g}-\mathrm{j}$ & $20.40 \mathrm{hi}$ & $11.40 \mathrm{f}-\mathrm{h}$ & 76.80 a-e & $33.0 \mathrm{ab}$ \\
\hline & V & $7.57 \mathrm{a}-\mathrm{g}$ & $57.23 \mathrm{~b}-\mathrm{j}$ & $28.71 \mathrm{k}$ & $17.63 \mathrm{kl}$ & $9.87 \mathrm{j}-1$ & 72.32 a-f & 29.8 b-f \\
\hline & $\mathrm{S}$ & $8.24 \mathrm{ab}$ & 60.39 a-e & $32.53 \mathrm{~g}-\mathrm{i}$ & $20.45 \mathrm{hi}$ & $11.71 \mathrm{e}-\mathrm{g}$ & $79.14 \mathrm{a}-\mathrm{d}$ & $30.4 \mathrm{~b}-\mathrm{e}$ \\
\hline & Average & $7.78 \mathrm{a}$ & $57.72 \mathrm{ab}$ & 30.18 e & $18.90 \mathrm{c}$ & $10.75 \mathrm{e}$ & $74.79 \mathrm{ab}$ & $27.99 \mathrm{ab}$ \\
\hline \multirow[t]{8}{*}{ F2 } & $\mathrm{K}$ & $8.10 \mathrm{ab}$ & 60.91 a-d & $28.87 \mathrm{k}$ & $18.00 \mathrm{kl}$ & $11.44 \mathrm{f}-\mathrm{h}$ & 76.73 a-e & $23.0 \mathrm{j}-1$ \\
\hline & $\mathrm{T}$ & $8.25 \mathrm{ab}$ & $58.55 \mathrm{a}-\mathrm{i}$ & $37.60 \mathrm{bc}$ & $24.48 \mathrm{c}$ & $12.46 \mathrm{c}-\mathrm{e}$ & $80.96 \mathrm{a}$ & 30.5 a-e \\
\hline & $\mathrm{P}$ & $6.85 \mathrm{~g}-\mathrm{i}$ & $56.00 \mathrm{c}-\mathrm{j}$ & $29.00 \mathrm{k}$ & $18.80 \mathrm{jk}$ & $10.72 \mathrm{hi}$ & $78.55 \mathrm{a}-\mathrm{d}$ & $27.5 \mathrm{~d}-\mathrm{i}$ \\
\hline & $\mathrm{L}$ & $7.87 \mathrm{a}-\mathrm{c}$ & $56.58 \mathrm{~b}-\mathrm{j}$ & $36.32 \mathrm{~cd}$ & $24.66 \mathrm{c}$ & $10.37 \mathrm{ij}$ & 77.82 a-e & $27.0 \mathrm{~d}-\mathrm{j}$ \\
\hline & $\mathrm{Z}$ & $7.65 \mathrm{a}-\mathrm{f}$ & $58.54 \mathrm{a}-\mathrm{i}$ & $32.20 \mathrm{~g}-\mathrm{j}$ & $21.50 \mathrm{f}-\mathrm{h}$ & $11.82 \mathrm{e}-\mathrm{g}$ & 73.95 a-e & $25.6 \mathrm{f}-\mathrm{k}$ \\
\hline & V & $7.57 \mathrm{a}-\mathrm{g}$ & $56.37 \mathrm{c}-\mathrm{j}$ & 24.311 & $15.94 \mathrm{~m}$ & $9.72 \mathrm{j}-1$ & $68.25 \mathrm{~b}-\mathrm{g}$ & $28.0 \mathrm{c}-\mathrm{h}$ \\
\hline & $\mathrm{S}$ & $8.31 \mathrm{a}$ & $60.83 \mathrm{a}-\mathrm{d}$ & $32.95 \mathrm{f}-\mathrm{h}$ & $21.66 \mathrm{f}-\mathrm{h}$ & $11.70 \mathrm{e}-\mathrm{g}$ & $79.43 \mathrm{a}-\mathrm{d}$ & $28.5 \mathrm{~b}-\mathrm{g}$ \\
\hline & Average & $7.80 \mathrm{a}$ & 58.26 ab & $31.61 \mathrm{~cd}$ & 20.72 b & $11.18 \mathrm{~d}$ & $76.53 \mathrm{ab}$ & $27.16 \mathrm{ab}$ \\
\hline \multirow[t]{8}{*}{ F3 } & $\mathrm{K}$ & $7.73 \mathrm{a}-\mathrm{e}$ & $52.22 \mathrm{j}-\mathrm{n}$ & $31.83 \mathrm{~g}-\mathrm{j}$ & $22.00 \mathrm{fg}$ & $12.80 \mathrm{~b}-\mathrm{d}$ & 77.52 a-e & $26.2 \mathrm{e}-\mathrm{j}$ \\
\hline & $\mathrm{T}$ & $7.99 \mathrm{ab}$ & 59.68 a-h & $34.90 \mathrm{~d}-\mathrm{f}$ & $23.70 \mathrm{c}-\mathrm{e}$ & $12.89 \mathrm{~b}-\mathrm{d}$ & 75.85 a-e & $26.1 \mathrm{e}-\mathrm{j}$ \\
\hline & $\mathrm{P}$ & $7.57 \mathrm{a}-\mathrm{g}$ & $57.09 \mathrm{~b}-\mathrm{j}$ & $32.00 \mathrm{~g}-\mathrm{j}$ & $21.26 \mathrm{~g}-\mathrm{i}$ & $11.10 \mathrm{~g}-\mathrm{i}$ & $82.02 \mathrm{a}$ & $23.0 \mathrm{j}-1$ \\
\hline & $\mathrm{L}$ & $7.97 \mathrm{ab}$ & $56.85 \mathrm{~b}-\mathrm{j}$ & $38.90 \mathrm{~b}$ & $21.80 \mathrm{f}-\mathrm{h}$ & $11.80 \mathrm{e}-\mathrm{g}$ & 75.36 a-e & $34.5 \mathrm{a}$ \\
\hline & $\mathrm{Z}$ & $7.60 \mathrm{a}-\mathrm{g}$ & $56.48 \mathrm{~b}-\mathrm{j}$ & $30.30 \mathrm{i}-\mathrm{k}$ & $19.80 \mathrm{ij}$ & $11.42 \mathrm{f}-\mathrm{h}$ & 75.59 a-e & $29.3 \mathrm{~b}-\mathrm{g}$ \\
\hline & V & $7.45 b-h$ & $54.23 \mathrm{e}-\mathrm{k}$ & $33.00 \mathrm{f}-\mathrm{h}$ & $22.09 \mathrm{fg}$ & $12.71 \mathrm{~b}-\mathrm{d}$ & $78.70 \mathrm{a}-\mathrm{d}$ & $26.8 \mathrm{~d}-\mathrm{j}$ \\
\hline & $\mathrm{S}$ & $8.30 \mathrm{a}$ & $59.05 \mathrm{a}-\mathrm{i}$ & $36.24 \mathrm{~cd}$ & $23.64 \mathrm{c}-\mathrm{e}$ & $13.14 \mathrm{bc}$ & $78.70 \mathrm{a}-\mathrm{d}$ & $29.7 \mathrm{~b}-\mathrm{f}$ \\
\hline & Average & $7.80 \mathrm{a}$ & $56.51 \mathrm{~b}$ & 33.88 bc & 22.04 a & 12.26 a & $77.68 \mathrm{a}$ & $27.94 \mathrm{ab}$ \\
\hline \multirow[t]{8}{*}{ F4 } & $\mathrm{K}$ & $7.81 \mathrm{a}-\mathrm{d}$ & $58.73 \mathrm{a}-\mathrm{i}$ & $46.30 \mathrm{a}$ & $29.10 \mathrm{a}$ & $15.04 \mathrm{a}$ & 75.77 a-e & $30.4 \mathrm{~b}-\mathrm{e}$ \\
\hline & $\mathrm{T}$ & $7.92 \mathrm{a}-\mathrm{c}$ & $57.36 \mathrm{~b}-\mathrm{j}$ & $35.91 \mathrm{c}-\mathrm{e}$ & $22.96 \mathrm{~d}-\mathrm{f}$ & $11.13 \mathrm{~g}-\mathrm{i}$ & $58.79 \mathrm{~g}$ & $30.1 \mathrm{~b}-\mathrm{e}$ \\
\hline & $\mathrm{P}$ & $6.86 \mathrm{~g}-\mathrm{i}$ & $53.80 \mathrm{~g}-1$ & $28.97 \mathrm{k}$ & $19.97 \mathrm{ij}$ & $9.30 \mathrm{k}-\mathrm{m}$ & $70.73 \mathrm{a}-\mathrm{f}$ & 24.0 h-1 \\
\hline & $\mathrm{L}$ & $7.80 \mathrm{a}-\mathrm{c}$ & $56.95 \mathrm{~b}-\mathrm{j}$ & $33.96 \mathrm{e}-\mathrm{g}$ & $20.41 \mathrm{hi}$ & $11.36 \mathrm{f}-\mathrm{h}$ & $77.51 \mathrm{a}-\mathrm{e}$ & $25.6 \mathrm{f}-\mathrm{k}$ \\
\hline & $\mathrm{Z}$ & 7.85 a-d & $59.98 \mathrm{a}-\mathrm{g}$ & $37.27 \mathrm{bc}$ & $21.80 \mathrm{f}-\mathrm{h}$ & $12.49 \mathrm{c}-\mathrm{e}$ & 78.46 a-d & 30.7 a-d \\
\hline & V & $7.60 \mathrm{a}-\mathrm{g}$ & $55.77 \mathrm{c}-\mathrm{j}$ & 34.90 d-f & $21.65 \mathrm{f}-\mathrm{h}$ & $11.53 \mathrm{f}-\mathrm{h}$ & 74.97 a-e & 29.4 b-g \\
\hline & $\mathrm{S}$ & $8.23 \mathrm{ab}$ & $59.86 \mathrm{a}-\mathrm{g}$ & $39.01 \mathrm{~b}$ & $24.60 \mathrm{c}$ & $12.75 \mathrm{~b}-\mathrm{d}$ & 77.69 a-e & $29.3 \mathrm{~b}-\mathrm{g}$ \\
\hline & Average & $7.72 \mathrm{a}$ & $57.49 \mathrm{ab}$ & $36.62 \mathrm{a}$ & 22.93 a & 11.94 bc & $73.42 \mathrm{~b}$ & 28.48 a \\
\hline \multirow[t]{10}{*}{ F5 } & $\mathrm{K}$ & $7.75 \mathrm{a}-\mathrm{e}$ & $56.88 \mathrm{~b}-\mathrm{j}$ & $33.42 \mathrm{f}-\mathrm{h}$ & $24.35 \mathrm{~cd}$ & $13.36 \mathrm{~b}$ & $78.85 \mathrm{a}-\mathrm{d}$ & $25.6 \mathrm{f}-\mathrm{k}$ \\
\hline & $\mathrm{T}$ & $7.92 \mathrm{a}-\mathrm{c}$ & $56.39 \mathrm{c}-\mathrm{j}$ & $31.34 \mathrm{~h}-\mathrm{j}$ & $19.82 \mathrm{ij}$ & $11.28 \mathrm{gh}$ & 75.69 a-e & 24.0 h-1 \\
\hline & $\mathrm{P}$ & $6.86 \mathrm{~g}-\mathrm{i}$ & $54.00 \mathrm{f}-\mathrm{k}$ & 24.901 & $17.17 \mathrm{~lm}$ & $9.92 \mathrm{jk}$ & $67.54 \mathrm{~d}-\mathrm{g}$ & 23.9 h-1 \\
\hline & $\mathrm{L}$ & $8.13 \mathrm{ab}$ & $59.87 \mathrm{a}-\mathrm{g}$ & $45.20 \mathrm{a}$ & $24.50 \mathrm{c}$ & $12.85 \mathrm{~b}-\mathrm{d}$ & 77.45 a-e & $30.9 \mathrm{a}-\mathrm{d}$ \\
\hline & $\mathrm{Z}$ & $7.81 \mathrm{a}-\mathrm{d}$ & $60.13 \mathrm{a}-\mathrm{g}$ & $31.30 \mathrm{~h}-\mathrm{j}$ & $19.83 \mathrm{ij}$ & $11.05 \mathrm{~g}-\mathrm{i}$ & 77.69 a-e & $30.3 \mathrm{~b}-\mathrm{e}$ \\
\hline & V & $7.45 \mathrm{~b}-\mathrm{h}$ & $58.17 \mathrm{a}-\mathrm{j}$ & $38.80 \mathrm{~b}$ & $26.08 \mathrm{~b}$ & $13.48 \mathrm{~b}$ & 76.69 a-e & $27.0 \mathrm{~d}-\mathrm{j}$ \\
\hline & $\mathrm{S}$ & $8.23 \mathrm{ab}$ & 60.56 a-e & $36.95 \mathrm{~b}-\mathrm{d}$ & $23.75 \mathrm{c}-\mathrm{e}$ & $12.95 \mathrm{~b}-\mathrm{d}$ & 77.33 a-e & $27.1 \mathrm{~d}-\mathrm{j}$ \\
\hline & Average & $7.74 \mathrm{a}$ & 58.08 ab & $34.56 \mathrm{~b}$ & 22.21 a & $12.13 \mathrm{ab}$ & $75.89 \mathrm{ab}$ & $26.97 \mathrm{~b}$ \\
\hline & $\mathrm{K}$ & $7.90 \mathrm{a}-\mathrm{c}$ & $58.02 \mathrm{a}-\mathrm{j}$ & $28.92 \mathrm{k}$ & $19.79 \mathrm{ij}$ & $10.78 \mathrm{hi}$ & $75.41 \mathrm{a}-\mathrm{e}$ & $26.8 \mathrm{~d}-\mathrm{j}$ \\
\hline & $\mathrm{T}$ & $8.06 \mathrm{ab}$ & $57.39 \mathrm{~b}-\mathrm{j}$ & $30.34 \mathrm{i}-\mathrm{k}$ & $20.46 \mathrm{hi}$ & $11.10 \mathrm{~g}-\mathrm{i}$ & 75.68 a-e & $31.1 \mathrm{a}-\mathrm{d}$ \\
\hline \multirow[t]{2}{*}{ Bio- } & $\mathrm{P}$ & $7.17 \mathrm{c}-\mathrm{i}$ & $53.53 \mathrm{~h}-\mathrm{m}$ & 34.87 d-f & $23.65 \mathrm{c}-\mathrm{e}$ & $11.42 \mathrm{f}-\mathrm{h}$ & $68.30 \mathrm{~b}-\mathrm{g}$ & $27.9 \mathrm{c}-\mathrm{h}$ \\
\hline & $\mathrm{L}$ & $7.97 \mathrm{ab}$ & $56.52 \mathrm{~b}-\mathrm{j}$ & $38.90 \mathrm{~b}$ & $24.60 \mathrm{c}$ & $12.50 \mathrm{c}-\mathrm{e}$ & $74.51 \mathrm{a}-\mathrm{e}$ & $27.7 \mathrm{~d}-\mathrm{h}$ \\
\hline \multirow[t]{4}{*}{ Fert. } & $\mathrm{Z}$ & $7.86 \mathrm{a}-\mathrm{d}$ & $62.81 \mathrm{ab}$ & $31.32 \mathrm{~h}-\mathrm{j}$ & $22.34 \mathrm{e}-\mathrm{g}$ & $11.86 \mathrm{e}-\mathrm{g}$ & $80.43 \mathrm{a}-\mathrm{c}$ & $23.2 \mathrm{i}-1$ \\
\hline & $\mathrm{V}$ & $7.47 \mathrm{~b}-\mathrm{h}$ & $57.10 \mathrm{~b}-\mathrm{j}$ & $33.70 \mathrm{e}-\mathrm{g}$ & $22.94 \mathrm{~d}-\mathrm{f}$ & $12.52 \mathrm{c}-\mathrm{e}$ & 75.89 a-e & $26.9 \mathrm{~d}-\mathrm{j}$ \\
\hline & $\mathrm{S}$ & $8.29 \mathrm{a}$ & $61.21 \mathrm{a}-\mathrm{c}$ & $34.85 \mathrm{~d}-\mathrm{f}$ & $23.78 \mathrm{c}-\mathrm{e}$ & $12.22 \mathrm{~d}-\mathrm{f}$ & $78.25 \mathrm{a}-\mathrm{d}$ & $28.8 \mathrm{~b}-\mathrm{g}$ \\
\hline & Average & $7.82 \mathrm{a}$ & 58.08 ab & 33.27 b-d & 22.51 a & $11.77 \mathrm{c}$ & $75.50 \mathrm{ab}$ & $27.48 \mathrm{ab}$ \\
\hline Appl. & $\mathrm{K}$ & $7.78 \mathrm{bc}$ & $55.82 \mathrm{c}$ & $32.59 \mathrm{bc}$ & $21.62 \mathrm{ab}$ & $11.99 \mathrm{a}$ & $77.23 \mathrm{a}$ & $26.75 \mathrm{a}$ \\
\hline \multirow[t]{6}{*}{ Av. } & $\mathrm{T}$ & $7.91 \mathrm{ab}$ & $56.75 \mathrm{bc}$ & $32.07 \mathrm{bc}$ & $20.94 \mathrm{~cd}$ & $11.27 \mathrm{~b}$ & $73.16 \mathrm{~b}$ & $27.17 \mathrm{a}$ \\
\hline & $\mathrm{P}$ & $6.86 \mathrm{e}$ & $53.43 \mathrm{~d}$ & $28.43 \mathrm{~d}$ & $18.89 \mathrm{f}$ & $10.07 \mathrm{c}$ & $69.26 \mathrm{c}$ & $24.19 b$ \\
\hline & $\mathrm{L}$ & $7.90 \mathrm{ab}$ & $56.96 \mathrm{bc}$ & $34.92 \mathrm{a}$ & $21.33 \mathrm{bc}$ & $11.03 \mathrm{~b}$ & $74.50 \mathrm{ab}$ & $27.57 \mathrm{a}$ \\
\hline & $\mathrm{Z}$ & $7.62 \mathrm{~cd}$ & $58.56 \mathrm{ab}$ & $31.39 \mathrm{c}$ & $20.18 \mathrm{e}$ & $11.18 \mathrm{~b}$ & $74.19 \mathrm{ab}$ & $27.25 \mathrm{a}$ \\
\hline & $\mathrm{V}$ & $7.41 \mathrm{~d}$ & $55.59 \mathrm{~cd}$ & $31.59 \mathrm{c}$ & $20.53 \mathrm{de}$ & $11.30 \mathrm{~b}$ & $73.66 \mathrm{ab}$ & $27.30 \mathrm{a}$ \\
\hline & $\mathrm{S}$ & $8.12 \mathrm{a}$ & $59.80 \mathrm{a}$ & $34.08 \mathrm{ab}$ & $22.05 \mathrm{a}$ & $11.80 \mathrm{a}$ & $76.53 \mathrm{ab}$ & $28.01 \mathrm{a}$ \\
\hline
\end{tabular}

* Control: No fertilizer and bacteria applied; NPK: $1400 \mathrm{mg}$ compound 25:5:10/seedling; The bacteria used in the F1F5 formulations are given in Table 1 and the description of the carriers is given on the previous page. 
**The differences between the means shown with the same letter are not significant $(\mathrm{p}<0.05)$ in their group.

Plant height, stem diameter, chlorophyll, second and third leaf area values were measured without cutting the seedlings, as in the first year of this experiment, which was established with two-years-old tea seedlings in Pazar-20 tea clone. The seedlings were cut from an equal height and harvested, stem+leaf, fresh and dry leaf weights were determined. Although it varies depending on the bacteria inoculated, fertilizer and carriers used, formulations, fertilizer applications, and carriers significantly increase the values of stem diameter, plant height, leaf number, branch+leaf weight, fresh and dry leaf weight, chlorophyll content, and second and third leaf area in tea seedlings affected. (Table $4 a, b)$.

NPK caused a significant increase in stem diameter and plant height compared to the control, and F2, F3, F5, and biological fertilizer applications were statistically in the same group according to the carrier averages. All applications except the F1 formulation increased the stem diameter, plant height, leaf number, branch+leaf weight, fresh and dry leaf weight, chlorophyll content, and second and third leaf area values in tea seedlings compared to the control, and the increasing rates were statistically significant was found $(p \leq 0.05)$ (Table $4 a, b)$.

F3, F5, and biological fertilizer formula, which showed high efficiency in branch+leaf weight, fresh and dry leaf weight, and leaf area, caused a significant increase in weight compared to mineral fertilizer application. The most suitable provider in terms of leaf weight and area gave the F3 formulation, which is more effective than mineral fertilization. According to the average fertilizer application, the liquid carrier gave the most suitable result in terms of measured parameters, followed by solid compost, leonardite, peat, and zeolite-based carriers, respectively. In terms of growth parameters, applications other than perlite generally belonged to the same statistical group. It has been determined that the compost-based carrier obtained from tea wastes stands out especially in terms of fresh and dry leaf weight and second and third leaf area. In terms of the parameters discussed, it was determined that the efficiency of the perlite-based solid carrier was low (Table 4a,b)

This experiment, which was established with young tea plants belonging to the Pazar 20 clone, was continued for two years (2013 and 2014), and the growth parameters were evaluated in both years. The results obtained indicate that all PGPR formulations produced significant increases in vegetative growth parameters compared to the control. The effectiveness of both bacterial formulations and carrier materials used together differ (Bai et al. 2014; Dutta et al. 20145; Jianyun et al. 2020).

Table 4a. The effect of a different carrier, bacterial combinations, and mineral fertilizer application on growth and yield parameters in Pazar-20 clone (2014)

\begin{tabular}{|c|c|c|c|c|c|c|}
\hline Treat. & 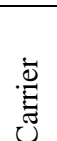 & $\begin{array}{l}\text { Trunk Diam. } \\
(\mathrm{mm})^{*}\end{array}$ & $\begin{array}{l}\text { Heigth of } \\
\text { Plant } \\
(\mathrm{cm})\end{array}$ & $\begin{array}{l}\text { Leaf+Shot } \\
\text { Weigth } \\
\text { (g/seedling) }\end{array}$ & $\begin{array}{l}\text { Fresh Leaf } \\
\text { Weigth } \\
\text { (g/seedling) }\end{array}$ & $\begin{array}{l}\text { Dry Leaf } \\
\text { Weight } \\
\text { (g/seedling }\end{array}$ \\
\hline
\end{tabular}

\begin{tabular}{lllllll}
\hline Control & $\mathrm{K}$ & $8.02 \mathrm{de}$ & $54.24 \mathrm{e}$ & $38.3 \mathrm{~g}$ & $19.07 \mathrm{~h}$ & $10.68 \mathrm{~h}$ \\
& $\mathrm{~T}$ & $7.82 \mathrm{e}$ & $54.77 \mathrm{e}$ & $40.9 \mathrm{fg}$ & $19.09 \mathrm{~h}$ & $10.80 \mathrm{~h}$ \\
& $\mathrm{P}$ & $7.66 \mathrm{e}$ & $54.31 \mathrm{e}$ & $37.9 \mathrm{~g}$ & $19.19 \mathrm{~h}$ & $10.80 \mathrm{~h}$ \\
& $\mathrm{~L}$ & $8.04 \mathrm{de}$ & $56.03 \mathrm{e}$ & $39.9 \mathrm{fg}$ & $19.20 \mathrm{~h}$ & $10.60 \mathrm{~h}$ \\
& $\mathrm{Z}$ & $7.82 \mathrm{e}$ & $54.76 \mathrm{e}$ & $40.6 \mathrm{fg}$ & $19.50 \mathrm{~h}$ & $10.70 \mathrm{~h}$ \\
& $\mathrm{~V}$ & $7.68 \mathrm{e}$ & $54.45 \mathrm{e}$ & $40.1 \mathrm{fg}$ & $19.88 \mathrm{~h}$ & $10.60 \mathrm{~h}$ \\
Average & $\mathrm{S}$ & $8.08 \mathrm{c}-\mathrm{e}$ & $59.92 \mathrm{de}$ & $38.5 \mathrm{~g}$ & $19.09 \mathrm{~h}$ & $10.80 \mathrm{~h}$ \\
\hline NPK & & $\mathbf{7 . 8 7} \mathbf{c}$ & $\mathbf{5 5 . 5 0} \mathbf{c}$ & $\mathbf{3 9 . 4} \mathrm{e}$ & $\mathbf{1 9 . 2 9} \mathrm{f}$ & $\mathbf{1 0 . 7 1 \mathrm { e }}$ \\
& $\mathrm{K}$ & $9.48 \mathrm{a}$ & $66.22 \mathrm{a}-\mathrm{d}$ & $50.9 \mathrm{c}$ & $25.00 \mathrm{f}$ & $13.50 \mathrm{c}-\mathrm{e}$ \\
& $\mathrm{T}$ & $9.58 \mathrm{a}$ & $65.63 \mathrm{a}-\mathrm{d}$ & $47.5 \mathrm{~d}$ & $25.08 \mathrm{f}$ & $13.16 \mathrm{c}-\mathrm{e}$ \\
& $\mathrm{P}$ & $8.85 \mathrm{a}-\mathrm{d}$ & $62.31 \mathrm{~b}-\mathrm{d}$ & $42.8 \mathrm{ef}$ & $22.10 \mathrm{~g}$ & $11.53 \mathrm{gh}$ \\
& $\mathrm{L}$ & $9.46 \mathrm{a}$ & $69.58 \mathrm{a}$ & $44.8 \mathrm{de}$ & $22.60 \mathrm{~g}$ & $12.06 \mathrm{fg}$ \\
Average & $\mathrm{Z}$ & $9.30 \mathrm{a}$ & $68.21 \mathrm{ab}$ & $45.6 \mathrm{de}$ & $22.90 \mathrm{~g}$ & $12.49 \mathrm{ef}$ \\
\hline F1 & $\mathrm{V}$ & $9.41 \mathrm{a}$ & $65.85 \mathrm{a}-\mathrm{d}$ & $51.1 \mathrm{c}$ & $25.32 \mathrm{f}$ & $13.51 \mathrm{~cd}$ \\
& $\mathrm{~S}$ & $9.50 \mathrm{a}$ & $69.63 \mathrm{a}$ & $54.4 \mathrm{ab}$ & $26.50 \mathrm{~d}-\mathrm{f}$ & $13.82 \mathrm{c}$ \\
\hline & & $\mathbf{9 . 3 7} \mathbf{a}$ & $\mathbf{6 6 . 7 7} \mathbf{~ a b}$ & $\mathbf{4 8 . 2 ~ c}$ & $\mathbf{2 4 . 2 1} \mathbf{c}$ & $\mathbf{1 2 . 8 7} \mathbf{c}$ \\
& $\mathrm{K}$ & $9.02 \mathrm{a}-\mathrm{d}$ & $62.37 \mathrm{~b}-\mathrm{d}$ & $39.5 \mathrm{fg}$ & $19.80 \mathrm{~h}$ & $10.80 \mathrm{~h}$ \\
& $\mathrm{~T}$ & $8.82 \mathrm{a}-\mathrm{d}$ & $64.63 \mathrm{a}-\mathrm{d}$ & $38.3 \mathrm{~g}$ & $19.12 \mathrm{~h}$ & $10.84 \mathrm{~h}$ \\
& $\mathrm{P}$ & $8.11 \mathrm{~b}-\mathrm{e}$ & $60.32 \mathrm{c}-\mathrm{e}$ & $38.0 \mathrm{~g}$ & $19.06 \mathrm{~h}$ & $10.81 \mathrm{~h}$ \\
& $\mathrm{~L}$ & $8.98 \mathrm{a}-\mathrm{d}$ & $67.29 \mathrm{a}-\mathrm{c}$ & $37.9 \mathrm{~g}$ & $19.14 \mathrm{~h}$ & $10.79 \mathrm{~h}$ \\
& $\mathrm{Z}$ & $9.09 \mathrm{a}-\mathrm{c}$ & $68.84 \mathrm{ab}$ & $37.9 \mathrm{~g}$ & $19.09 \mathrm{~h}$ & $10.69 \mathrm{~h}$ \\
& $\mathrm{~V}$ & $8.97 \mathrm{a}-\mathrm{d}$ & $65.02 \mathrm{a}-\mathrm{d}$ & $37.9 \mathrm{~g}$ & $19.02 \mathrm{~h}$ & $10.64 \mathrm{~h}$
\end{tabular}


Ertürk et al. / Manas Journal of Agriculture Veterinary and Life Sciences 11 (2) (2021) 109-119

\begin{tabular}{|c|c|c|c|c|c|c|}
\hline \multirow[b]{2}{*}{ Average } & $\mathrm{S}$ & $9.49 \mathrm{a}$ & $67.93 \mathrm{ab}$ & $38.1 \mathrm{~g}$ & $19.38 \mathrm{~h}$ & $10.78 \mathrm{~h}$ \\
\hline & & $8.93 \mathrm{~b}$ & $65.20 \mathrm{~b}$ & $38.2 \mathrm{e}$ & $19.23 \mathrm{f}$ & 10.77 e \\
\hline \multirow[t]{7}{*}{ F2 } & $\mathrm{K}$ & $9.19 \mathrm{a}$ & $67.28 \mathrm{a}-\mathrm{c}$ & $41.2 \mathrm{fg}$ & $20.13 \mathrm{~h}$ & $12.00 \mathrm{fg}$ \\
\hline & $\mathrm{T}$ & $9.33 \mathrm{a}$ & $66.10 \mathrm{a}-\mathrm{d}$ & $47.3 \mathrm{~d}$ & $22.60 \mathrm{~g}$ & $12.50 \mathrm{ef}$ \\
\hline & $\mathrm{P}$ & 8.80 a-d & $63.62 \mathrm{~b}-\mathrm{d}$ & $41.3 \mathrm{fg}$ & $20.50 \mathrm{~h}$ & $11.30 \mathrm{gh}$ \\
\hline & $\mathrm{L}$ & $9.34 \mathrm{a}$ & $64.28 \mathrm{a}-\mathrm{d}$ & $47.5 \mathrm{~d}$ & $22.30 \mathrm{~g}$ & $12.69 \mathrm{~d}-\mathrm{f}$ \\
\hline & $\mathrm{Z}$ & $9.30 \mathrm{a}$ & $66.51 \mathrm{a}-\mathrm{d}$ & $45.9 \mathrm{de}$ & $22.80 \mathrm{~g}$ & $12.60 \mathrm{e}-\mathrm{f}$ \\
\hline & V & 8.96 a-d & $64.03 \mathrm{a}-\mathrm{d}$ & $40.6 \mathrm{fg}$ & $19.05 \mathrm{~h}$ & $11.36 \mathrm{gh}$ \\
\hline & $\mathrm{S}$ & $9.66 \mathrm{a}$ & $67.53 \mathrm{ab}$ & $47.2 \mathrm{~d}$ & $23.40 \mathrm{~g}$ & $12.90 \mathrm{c}-\mathrm{f}$ \\
\hline \multicolumn{2}{|l|}{ Average } & $9.22 \mathrm{ab}$ & $65.62 \mathrm{ab}$ & $44.4 \mathrm{~d}$ & $21.54 \mathrm{e}$ & $12.19 \mathrm{~d}$ \\
\hline \multirow[t]{7}{*}{ F3 } & $\mathrm{K}$ & $9.76 \mathrm{a}$ & $68.56 \mathrm{ab}$ & $54.8 \mathrm{ab}$ & $29.25 \mathrm{ab}$ & $15.30 \mathrm{ab}$ \\
\hline & $\mathrm{T}$ & $9.87 \mathrm{a}$ & $67.80 \mathrm{ab}$ & $56.7 \mathrm{a}$ & $30.20 \mathrm{a}$ & $15.70 \mathrm{ab}$ \\
\hline & $\mathrm{P}$ & $9.23 \mathrm{a}$ & $64.85 \mathrm{a}-\mathrm{d}$ & $55.0 \mathrm{ab}$ & $28.70 \mathrm{a}-\mathrm{c}$ & $15.00 \mathrm{ab}$ \\
\hline & $\mathrm{L}$ & $9.12 a b$ & $65.64 \mathrm{a}-\mathrm{d}$ & $56.6 \mathrm{a}$ & $29.23 \mathrm{ab}$ & $15.87 \mathrm{a}$ \\
\hline & $\mathrm{Z}$ & $9.30 \mathrm{a}$ & $64.16 \mathrm{a}-\mathrm{d}$ & $52.1 \mathrm{bc}$ & $27.30 \mathrm{c}-\mathrm{e}$ & $14.80 \mathrm{~b}$ \\
\hline & V & $9.43 \mathrm{a}$ & $66.77 \mathrm{a}-\mathrm{d}$ & $56.7 \mathrm{a}$ & $30.26 \mathrm{a}$ & $15.90 \mathrm{a}$ \\
\hline & $\mathrm{S}$ & $9.79 \mathrm{a}$ & $67.08 \mathrm{a}-\mathrm{c}$ & $57.8 \mathrm{a}$ & $30.20 \mathrm{a}$ & $15.87 \mathrm{a}$ \\
\hline \multicolumn{2}{|l|}{ Average } & $9.50 \mathrm{a}$ & $66.41 \mathrm{ab}$ & 55.7 a & 29.31 a & $15.49 \mathrm{a}$ \\
\hline \multirow[t]{7}{*}{$\mathrm{F} 4$} & $\mathrm{~K}$ & $9.26 \mathrm{a}$ & $66.72 \mathrm{a}-\mathrm{d}$ & $54.9 \mathrm{ab}$ & $28.70 \mathrm{a}-\mathrm{c}$ & $15.19 \mathrm{ab}$ \\
\hline & $\mathrm{T}$ & $9.26 \mathrm{a}$ & $63.36 \mathrm{~b}-\mathrm{d}$ & $42.9 \mathrm{ef}$ & $22.33 \mathrm{~g}$ & $10.60 \mathrm{~h}$ \\
\hline & $\mathrm{P}$ & $8.10 \mathrm{~b}-\mathrm{e}$ & $60.28 \mathrm{c}-\mathrm{e}$ & $40.3 \mathrm{fg}$ & $20.16 \mathrm{~h}$ & $10.61 \mathrm{~h}$ \\
\hline & $\mathrm{L}$ & $8.81 \mathrm{a}-\mathrm{d}$ & $64.69 \mathrm{a}-\mathrm{d}$ & $40.6 \mathrm{fg}$ & $22.18 \mathrm{~g}$ & $11.41 \mathrm{gh}$ \\
\hline & $\mathrm{Z}$ & $8.86 \mathrm{a}-\mathrm{d}$ & $66.92 \mathrm{a}-\mathrm{c}$ & $44.8 \mathrm{de}$ & $23.00 \mathrm{~g}$ & $12.51 \mathrm{ef}$ \\
\hline & V & $9.02 \mathrm{a}-\mathrm{d}$ & $63.35 \mathrm{a}-\mathrm{d}$ & $42.8 \mathrm{ef}$ & $22.14 \mathrm{~g}$ & $12.21 \mathrm{e}-\mathrm{g}$ \\
\hline & $\mathrm{S}$ & $9.22 \mathrm{a}$ & $65.47 \mathrm{a}-\mathrm{d}$ & $44.8 \mathrm{de}$ & $23.20 \mathrm{~g}$ & $12.57 \mathrm{~d}-\mathrm{f}$ \\
\hline \multicolumn{2}{|l|}{ Average } & $8.93 \mathrm{~b}$ & $64.40 \mathrm{~b}$ & $44.4 \mathrm{~d}$ & $23.10 \mathrm{~d}$ & $12.16 \mathrm{~d}$ \\
\hline \multirow[t]{7}{*}{ F5 } & $\mathrm{K}$ & $9.34 \mathrm{a}$ & $68.37 \mathrm{ab}$ & $54.4 \mathrm{ab}$ & $27.80 \mathrm{~b}-\mathrm{d}$ & $14.90 \mathrm{ab}$ \\
\hline & $\mathrm{T}$ & $9.69 \mathrm{a}$ & $66.14 \mathrm{a}-\mathrm{d}$ & $51.0 \mathrm{c}$ & $22.63 \mathrm{~g}$ & $12.58 \mathrm{~d}-\mathrm{f}$ \\
\hline & $\mathrm{P}$ & $8.95 \mathrm{a}-\mathrm{d}$ & $63.25 \mathrm{~b}-\mathrm{d}$ & $42.8 \mathrm{ef}$ & $22.30 \mathrm{~g}$ & $11.31 \mathrm{gh}$ \\
\hline & $\mathrm{L}$ & $9.43 \mathrm{a}$ & $69.83 \mathrm{a}$ & $54.9 \mathrm{ab}$ & $27.29 \mathrm{c}-\mathrm{e}$ & $14.83 \mathrm{~b}$ \\
\hline & $\mathrm{Z}$ & $9.12 \mathrm{ab}$ & $68.31 \mathrm{ab}$ & $50.9 \mathrm{c}$ & $25.90 \mathrm{ef}$ & $13.67 \mathrm{c}$ \\
\hline & $\mathrm{V}$ & $9.58 \mathrm{a}$ & $69.15 \mathrm{ab}$ & $57.2 \mathrm{a}$ & $29.20 \mathrm{ab}$ & $15.80 \mathrm{ab}$ \\
\hline & $\mathrm{S}$ & $9.59 \mathrm{a}$ & $68.79 \mathrm{ab}$ & $56.2 \mathrm{a}$ & $29.21 \mathrm{ab}$ & $15.18 \mathrm{ab}$ \\
\hline \multicolumn{2}{|l|}{ Average } & $9.39 \mathrm{a}$ & $67.69 \mathrm{a}$ & $52.5 \mathrm{~b}$ & $26.33 \mathrm{~b}$ & $14.04 \mathrm{~b}$ \\
\hline \multirow[t]{7}{*}{ Bio- Fert. } & $\mathrm{K}$ & $9.23 \mathrm{a}$ & $65.91 \mathrm{a}-\mathrm{d}$ & $52.4 \mathrm{bc}$ & $25.60 \mathrm{f}$ & $14.80 \mathrm{~b}$ \\
\hline & $\mathrm{T}$ & $9.39 \mathrm{a}$ & $64.50 \mathrm{a}-\mathrm{d}$ & $55.0 \mathrm{ab}$ & $26.46 \mathrm{~d}-\mathrm{f}$ & $14.93 \mathrm{ab}$ \\
\hline & $\mathrm{P}$ & $9.12 \mathrm{ab}$ & $65.82 \mathrm{a}-\mathrm{d}$ & $54.4 \mathrm{ab}$ & $26.64 d-f$ & $14.94 \mathrm{ab}$ \\
\hline & $\mathrm{L}$ & $9.27 \mathrm{a}$ & $65.59 \mathrm{a}-\mathrm{d}$ & $57.6 \mathrm{a}$ & $27.26 \mathrm{c}-\mathrm{e}$ & $15.90 \mathrm{a}$ \\
\hline & $\mathrm{Z}$ & $9.18 \mathrm{a}$ & $69.65 \mathrm{a}$ & $56.7 \mathrm{a}$ & $27.70 \mathrm{~b}-\mathrm{d}$ & $15.26 \mathrm{ab}$ \\
\hline & $\mathrm{V}$ & $9.18 \mathrm{a}$ & $64.86 \mathrm{a}-\mathrm{d}$ & $56.3 \mathrm{a}$ & $27.40 \mathrm{c}-\mathrm{e}$ & $15.30 \mathrm{ab}$ \\
\hline & $\mathrm{S}$ & $9.09 \mathrm{a}-\mathrm{c}$ & $67.35 \mathrm{ab}$ & $56.7 \mathrm{a}$ & $27.80 \mathrm{~b}-\mathrm{d}$ & $15.40 \mathrm{ab}$ \\
\hline \multicolumn{2}{|l|}{ Average } & $9.21 \mathrm{ab}$ & $66.24 \mathrm{ab}$ & 55.6 a & $26.98 \mathrm{~b}$ & $15.22 \mathrm{a}$ \\
\hline \multirow{7}{*}{$\begin{array}{l}\text { Treat. } \\
\text { Average }\end{array}$} & $\mathrm{K}$ & $9.16 \mathrm{a}$ & $64.96 \mathrm{a}$ & $48.3 \mathrm{a}$ & $24.42 \mathrm{a}$ & $13.40 \mathrm{a}$ \\
\hline & $\mathrm{T}$ & $9.22 \mathrm{a}$ & $64.12 \mathrm{ab}$ & $47.4 \mathrm{ab}$ & $23.44 \mathrm{ab}$ & $12.64 \mathrm{ab}$ \\
\hline & $\mathrm{P}$ & $8.60 \mathrm{~b}$ & $61.84 \mathrm{~b}$ & $44.1 \mathrm{~b}$ & $22.33 \mathrm{~b}$ & $12.04 \mathrm{~b}$ \\
\hline & $\mathrm{L}$ & $9.06 \mathrm{a}$ & $65.37 \mathrm{a}$ & $47.5 \mathrm{ab}$ & $23.65 \mathrm{ab}$ & $13.02 \mathrm{a}$ \\
\hline & $\mathrm{Z}$ & $9.00 \mathrm{a}$ & $65.92 \mathrm{a}$ & $46.8 \mathrm{ab}$ & $23.52 \mathrm{ab}$ & $12.84 \mathrm{ab}$ \\
\hline & V & $9.03 \mathrm{a}$ & $64.18 \mathrm{ab}$ & $47.8 \mathrm{a}$ & $24.03 \mathrm{ab}$ & $13.16 \mathrm{a}$ \\
\hline & $\mathrm{S}$ & $9.30 \mathrm{a}$ & $66.71 \mathrm{a}$ & $49.2 \mathrm{a}$ & $24.85 \mathrm{a}$ & $13.42 \mathrm{a}$ \\
\hline
\end{tabular}

* The differences between the means indicated with the same column are not significant in their group $(\mathrm{p}<0.05)$.

Table 4.b. The effect of a different carrier, bacterial combinations, and mineral fertilizer application on yield and growth parameters in Pazar-20 clone (2014)

\begin{tabular}{|c|c|c|c|c|}
\hline Treatment & $\tilde{U}_{\tilde{E}}^{E}$ & $\begin{array}{l}\text { Clorofil } \\
\text { (SPAD) } \\
\text { content }\end{array}$ & $\begin{array}{l}\text { Second Leaf Area } \\
\left(\mathrm{cm}^{2}\right)\end{array}$ & $\begin{array}{l}\text { Third Leaf area } \\
\left(\mathrm{cm}^{2}\right.\end{array}$ \\
\hline \multirow[t]{7}{*}{ Control } & $\mathrm{K}$ & $69.84 \mathrm{c}-\mathrm{g}$ & $12.08 \mathrm{~g}$ & $21.18 \mathrm{~h}$ \\
\hline & $\mathrm{T}$ & $66.30 \mathrm{fg}$ & $12.36 \mathrm{~g}$ & $21.67 \mathrm{~h}$ \\
\hline & $\mathrm{P}$ & $64.88 \mathrm{~g}$ & $12.13 \mathrm{~g}$ & $21.26 \mathrm{~h}$ \\
\hline & $\mathrm{L}$ & $64.85 \mathrm{~g}$ & $12.49 \mathrm{~g}$ & $21.91 \mathrm{~h}$ \\
\hline & $\mathrm{Z}$ & $64.83 \mathrm{~g}$ & $12.77 \mathrm{fg}$ & $22.25 \mathrm{~h}$ \\
\hline & V & $64.83 \mathrm{~g}$ & $12.85 \mathrm{fg}$ & $22.68 \mathrm{~h}$ \\
\hline & $\mathrm{S}$ & $64.96 \mathrm{~g}$ & $12.10 \mathrm{~g}$ & $21.22 \mathrm{~h}$ \\
\hline Average & & $65.78 \mathrm{~d}$ & $12.40 \mathrm{e}$ & $21.74 \mathrm{f}$ \\
\hline
\end{tabular}




\begin{tabular}{|c|c|c|c|c|}
\hline \multirow[t]{7}{*}{ NPK } & $\mathrm{K}$ & $77.27 \mathrm{a}$ & $15.31 \mathrm{~cd}$ & $27.25 \mathrm{c}-\mathrm{f}$ \\
\hline & $\mathrm{T}$ & $77.26 \mathrm{a}$ & $14.63 \mathrm{de}$ & $26.91 \mathrm{ef}$ \\
\hline & $\mathrm{P}$ & 72.09 a-f & $14.00 \mathrm{e}$ & $24.40 \mathrm{~g}$ \\
\hline & $\mathrm{L}$ & $74.95 \mathrm{a}-\mathrm{d}$ & $13.73 \mathrm{ef}$ & $24.72 \mathrm{~g}$ \\
\hline & Z & $74.18 \mathrm{a}-\mathrm{d}$ & $13.95 \mathrm{e}$ & $24.72 \mathrm{~g}$ \\
\hline & V & $77.24 \mathrm{a}$ & $15.28 \mathrm{~cd}$ & $26.98 \mathrm{ef}$ \\
\hline & $\mathrm{S}$ & $77.01 \mathrm{ab}$ & $15.86 \mathrm{a}-\mathrm{c}$ & $28.17 \mathrm{a}-\mathrm{e}$ \\
\hline \multicolumn{2}{|l|}{ Average } & $75.71 \mathrm{a}$ & $14.68 \mathrm{c}$ & $26.12 \mathrm{c}$ \\
\hline \multirow[t]{7}{*}{$\mathrm{F} 1$} & $\mathrm{~K}$ & $73.10 \mathrm{a}-\mathrm{f}$ & $12.88 \mathrm{fg}$ & $22.19 \mathrm{~h}$ \\
\hline & $\mathrm{T}$ & $70.92 \mathrm{a}-\mathrm{g}$ & $12.10 \mathrm{~g}$ & $21.91 \mathrm{~h}$ \\
\hline & $\mathrm{P}$ & $68.33 \mathrm{~d}-\mathrm{g}$ & $12.09 \mathrm{~g}$ & $21.48 \mathrm{~h}$ \\
\hline & $\mathrm{L}$ & $71.06 \mathrm{a}-\mathrm{g}$ & $12.24 \mathrm{~g}$ & $21.57 \mathrm{~h}$ \\
\hline & $\mathrm{Z}$ & 72.86 a-f & $12.42 \mathrm{~g}$ & $21.39 \mathrm{~h}$ \\
\hline & $\mathrm{V}$ & $66.57 \mathrm{e}-\mathrm{g}$ & $12.17 \mathrm{~g}$ & $21.28 \mathrm{~h}$ \\
\hline & $\mathrm{S}$ & $71.12 \mathrm{a}-\mathrm{g}$ & $12.89 \mathrm{fg}$ & $22.36 \mathrm{~h}$ \\
\hline \multicolumn{2}{|l|}{ Average } & $70.57 \mathrm{c}$ & $12.40 \mathrm{e}$ & $21.74 \mathrm{f}$ \\
\hline \multirow[t]{7}{*}{ F2 } & $\mathrm{K}$ & 72.51 a-f & $12.77 \mathrm{fg}$ & $22.79 \mathrm{~h}$ \\
\hline & $\mathrm{T}$ & 73.32 a-e & $13.73 \mathrm{ef}$ & $25.33 \mathrm{~g}$ \\
\hline & $\mathrm{P}$ & $70.70 \mathrm{a}-\mathrm{g}$ & $12.73 \mathrm{fg}$ & $22.77 \mathrm{~h}$ \\
\hline & $\mathrm{L}$ & $77.29 \mathrm{a}$ & $13.79 \mathrm{ef}$ & $24.40 \mathrm{~g}$ \\
\hline & Z & 71.71 a-f & $13.95 \mathrm{e}$ & $24.51 \mathrm{~g}$ \\
\hline & $\mathrm{V}$ & $69.89 \mathrm{c}-\mathrm{g}$ & $12.04 \mathrm{~g}$ & $21.25 \mathrm{~h}$ \\
\hline & $\mathrm{S}$ & $71.86 \mathrm{a}-\mathrm{f}$ & $14.22 \mathrm{e}$ & $27.22 \mathrm{c}-\mathrm{f}$ \\
\hline \multicolumn{2}{|l|}{ Average } & $72.47 \mathrm{bc}$ & $13.32 \mathrm{~d}$ & 24.04 e \\
\hline \multirow[t]{7}{*}{ F3 } & $\mathrm{K}$ & $74.00 \mathrm{a}-\mathrm{d}$ & $16.11 \mathrm{a}-\mathrm{c}$ & $29.61 \mathrm{a}$ \\
\hline & $\mathrm{T}$ & $76.32 \mathrm{a}-\mathrm{c}$ & $16.63 \mathrm{ab}$ & $29.56 \mathrm{a}$ \\
\hline & $\mathrm{P}$ & $75.73 \mathrm{a}-\mathrm{c}$ & $15.81 \mathrm{a}-\mathrm{c}$ & $28.76 \mathrm{a}-\mathrm{d}$ \\
\hline & $\mathrm{L}$ & $74.17 \mathrm{a}-\mathrm{d}$ & $16.21 \mathrm{a}-\mathrm{c}$ & 29.79 a \\
\hline & $\mathrm{Z}$ & 71.78 a-f & $15.24 \mathrm{~cd}$ & $27.63 \mathrm{~b}-\mathrm{e}$ \\
\hline & V & 73.18 a-f & $16.78 \mathrm{a}$ & $29.83 \mathrm{a}$ \\
\hline & $\mathrm{S}$ & $70.26 \mathrm{~b}-\mathrm{g}$ & $16.80 \mathrm{a}$ & $29.77 \mathrm{a}$ \\
\hline \multicolumn{2}{|l|}{ Average } & $73.63 \mathrm{~b}$ & $16.23 \mathrm{a}$ & 29.28 a \\
\hline \multirow[t]{7}{*}{ F4 } & $\mathrm{K}$ & 72.02 a-f & $16.81 \mathrm{a}$ & $29.28 \mathrm{ab}$ \\
\hline & $\mathrm{T}$ & $70.44 \mathrm{a}-\mathrm{g}$ & $13.68 \mathrm{ef}$ & $24.48 \mathrm{~g}$ \\
\hline & $\mathrm{P}$ & $66.36 \mathrm{fg}$ & $12.11 \mathrm{~g}$ & $21.47 \mathrm{~h}$ \\
\hline & $\mathrm{L}$ & 72.72 a-f & $12.58 \mathrm{~g}$ & $24.41 \mathrm{~g}$ \\
\hline & $\mathrm{Z}$ & $71.47 \mathrm{a}-\mathrm{g}$ & $13.79 \mathrm{ef}$ & $25.26 \mathrm{~g}$ \\
\hline & V & $69.56 \mathrm{c}-\mathrm{g}$ & $12.76 \mathrm{fg}$ & $24.46 \mathrm{~g}$ \\
\hline & $\mathrm{S}$ & 72.70 a-f & $14.09 \mathrm{e}$ & $24.94 \mathrm{~g}$ \\
\hline \multicolumn{2}{|l|}{ Average } & 70.75 c & $13.69 \mathrm{~d}$ & $24.90 \mathrm{~d}$ \\
\hline \multirow[t]{7}{*}{ F5 } & $\mathrm{K}$ & $74.66 \mathrm{a}-\mathrm{d}$ & $16.81 \mathrm{a}$ & $28.84 \mathrm{a}-\mathrm{c}$ \\
\hline & $\mathrm{T}$ & 73.15 a-f & $14.69 \mathrm{de}$ & $25.65 \mathrm{fg}$ \\
\hline & $\mathrm{P}$ & $68.50 \mathrm{~d}-\mathrm{g}$ & $12.46 \mathrm{~g}$ & $24.55 \mathrm{~g}$ \\
\hline & $\mathrm{L}$ & $76.19 \mathrm{a}-\mathrm{c}$ & $16.49 \mathrm{ab}$ & $29.51 \mathrm{a}$ \\
\hline & Z & 73.03 a-f & $15.65 b-d$ & 26.99 ef \\
\hline & V & 72.51 a-f & $16.72 \mathrm{ab}$ & $29.77 \mathrm{a}$ \\
\hline & $\mathrm{S}$ & 73.16 a-f & $16.80 \mathrm{a}$ & $29.66 \mathrm{a}$ \\
\hline \multicolumn{2}{|l|}{ Average } & 73.03 b & $15.66 \mathrm{~b}$ & $27.85 \mathrm{~b}$ \\
\hline \multirow[t]{7}{*}{ Bio- Fert. } & $\mathrm{K}$ & $70.13 \mathrm{~b}-\mathrm{g}$ & $15.27 \mathrm{~cd}$ & 27.55 c-e \\
\hline & $\mathrm{T}$ & 71.66 a-f & $16.08 \mathrm{a}-\mathrm{c}$ & $27.45 \mathrm{c}-\mathrm{e}$ \\
\hline & $\mathrm{P}$ & $70.04 \mathrm{c}-\mathrm{g}$ & $15.82 \mathrm{a}-\mathrm{c}$ & 27.09 d-f \\
\hline & $\mathrm{L}$ & 73.90 a-d & $16.80 \mathrm{a}$ & 28.41 a-e \\
\hline & Z & $73.84 \mathrm{a}-\mathrm{d}$ & $16.77 \mathrm{a}$ & $28.74 \mathrm{a}-\mathrm{d}$ \\
\hline & $\mathrm{V}$ & $70.04 \mathrm{c}-\mathrm{g}$ & $16.65 \mathrm{ab}$ & 28.22 a-e \\
\hline & $\mathrm{S}$ & $71.34 \mathrm{a}-\mathrm{g}$ & $16.81 \mathrm{a}$ & $28.84 \mathrm{a}-\mathrm{c}$ \\
\hline \multicolumn{2}{|l|}{ Average } & 71.56 bc & $16.31 \mathrm{a}$ & 28.04 b \\
\hline \multirow[t]{2}{*}{ Treatment } & $\mathrm{K}$ & $72.94 \mathrm{ab}$ & $14.75 \mathrm{a}$ & $26.09 \mathrm{a}$ \\
\hline & $\mathrm{T}$ & $72.42 \mathrm{ab}$ & $14.24 \mathrm{a}$ & $25.37 \mathrm{ab}$ \\
\hline Average & $\mathrm{P}$ & $69.58 \mathrm{c}$ & $13.39 \mathrm{~b}$ & $23.97 \mathrm{~b}$ \\
\hline & $\mathrm{L}$ & $73.14 \mathrm{a}$ & $14.29 \mathrm{a}$ & $25.55 \mathrm{a}$ \\
\hline & $\mathrm{Z}$ & $71.71 \mathrm{a}-\mathrm{c}$ & $14.32 \mathrm{a}$ & $25.19 \mathrm{ab}$ \\
\hline & $\mathrm{V}$ & 70.48 bc & $14.41 \mathrm{a}$ & $25.56 \mathrm{a}$ \\
\hline & $\mathrm{S}$ & $71.55 \mathrm{a}-\mathrm{c}$ & $14.95 \mathrm{a}$ & $26.52 \mathrm{a}$ \\
\hline
\end{tabular}




\section{CONCLUSION}

Bacterial association with root growth is an important innovative field of agricultural research. Inoculation with triple bacteria increased plant height, trunk diameter, shoot and leaf weight, chlorophyll value in tea seedlings compared with the control. Furthermore, the positive effects of PGPR on plant growth were correlated with remarkable changes in root growth and morphology, namely increasing the lateral root and root hair number and length. Previous studies also demonstrated the application of PGPR in soil has resulted in a significant increase in the growth of young tea seedlings (Gulati et al. 2011; Bagyalakshimi et al. 2012; Chakraborty et al. 2015; Princy et al. 2015; Bhattacharyya et al. 2015; 2020; Fauziah et al. 2019; Tennakon et al. 2019; Wang et al. 2020; Shang and Liu 2020). and help reduce the use of chemicals in tea plantations (Charaborty et al. 2009).

It was determined that almost all strains had nitrogen fixation and phosphate solubilization capacity in laboratory tests of the bacterial isolates used in triples, forming the F1, F2, F3, F4, and F5 formulations used in this experiment (Table 1). Thus, better use of phosphorus in the soil by plants from a young age will lead to good rooting, and through the mechanism created by bacteria with nitrogen fixation ability, the nitrogen they will need for growth and development will be fully supplied. In addition, although other instruments such as siderophore and IAA production of these isolates have not been tested, it may be possible that at least some of the bacteria used have these properties. As a matter of fact, it was determined in another study (Çakmakçı et. al. 2010) and different geographies (Gulati et al. 2011; Fauziah et al. 2019) that many other mechanisms could be together in many of the rhizobacteria isolated from nature.

Especially in terms of carriers, significant differences compared to the control were observed in both years (Tables 2 and 3). So much so that in 2013 and 2014, the liquid organic carrier (S) produced the highest values in terms of almost all parameters. However, other carriers that followed caused different results in different parameters, and the lowest values were generally obtained when the perlite (P) carrier was used (Tables 3 and 4a,b).

The test results indicated that F1, F2, F3, F4, and F5 biofertilizer formulations could promote the growth of the plant. The mechanisms may include the follows: first, some amino acids and lipid substances produced by these formulations containing triple bacteria could promote the growth and development of plants and the balance of soil mineral nutrients, such as the phytase generated from the metabolism, which could help to convert the unabsorbable inorganic and organic phosphorus in the soil into the absorbable phosphorus, improving phosphorus absorption efficiency of plants. In addition, many plant growth-promoting bacteria have been verified to produce plant growth regulators in the plant rhizosphere, such as IAA, cytokinins, and other plant hormones, to promote plant growth and increase yield (Glick 1995).

Selected bacterial strains stimulated overall plant growth, including shoot development, plant height, trunk diameter, leaf yield, and chlorophyll parameters of Turkish registered tea clones Pazar-20.

\section{CONFLICT OF INTERESTS}

There is no conflict of interest between the authors

\section{AUTHORS CONTRIBUTION}

Yaşar ERTÜRK; Planning, field studies, evaluation, writing

Ramazan Çakmakçı; Planning, field studies, statical analysis, evaluation,

Meral KUTLU; Field studies

Hakan KELES; Field studies

\section{ACKNOWLEDGMENTS}

This work is financially supported by the Scientific and Technological Research Council of Turkey (TOVAG; $112 \mathrm{O}$ 313 project).

\section{REFERENCES}

Amutha M, Arunachalam R, Umamaheswari M, Usharamalakshmi A, Ramakrishnan S, Annadurai G 2010. Medicinal use of Camellia sinensis on lactose intolerance. J. Of Biol. Sci. 10 (2):112-116. ISSN 1727-3048.

Bai Z, Zhou C, Cao J, Xu Ş, Wu S, Li D 2014. Effects of Bacillus amyloliquefaciens Biofertilizer on Tea Yield and Quality. Agricultural Science \& Technology, 15(11): 1883-1887. 
Bagyalakshmi B, Balamurugan A, Panmurugan P, Premkumar R 2012. Compatibility study of indigenous plant growth promoting rhizobacteria with inorganic and fertilizers used in Tea (Camellia sinensis). Int. J. Of Agr. Research 7(3):144-151.

Bhattacharyya PN, Sarmah SR, Dutta P, Tanti AJ 2015. Emergence in mapping microbial diversity in tea (Camellia sinensis (L.) O. Kuntze) soil of Assam, North-East India: A novel approach. European J. of Biotechnology and Bioscience. 3 (12):20-25.

Bhattacharyya C, Banerjee S, Acharya U, Mitra A, Mallick I, Haldar A, Haldar S, Ghosh A, Ghosh A 2020. Evaluation of plant growth properties and induction of antioxidative defense mechanism by tea rhizobacteria of Darjeeling, India. Scientific Reports, https://doi.org/10.1038/s41598-020-72439-z.

Chakraborty APC, Chakraborty U 2015. Bacillus megaterium from tea rhizosphere promotes growth and induces systemic resistance in tea against Sclerotium rolfsii. Indian Phytopathol. 68, 237-247.

Chakraborty U, Chakraborty BN, Basnet M, Chakraborty AP 2009. Evaluation of Ochrobactrum anthropi TRS-2 and its talc based formulation for enhancement of growth of tea plants and management of brown root rot disease. J. Appl. Microbiol., 107,625-634. https ://doi.org/10.1111/j.1365-2672.2009.04242 .x

Chakraborty U, Chakraborty BN, Chakraborty AP 2012. Induction of plant growth promotion in Camellia sinensis by Bacillus megaterium and its bioformulations. World J. Agric. Sci. 8, (1), 104-112.

Çakmakçı R, Dönmez MF, Ertürk Y, Erat M, Haznedar A, Sekban R 2010. Diversity and metabolic potential of culturable bacteria from the rhizosphere of Turkish tea grown in acidic soils, Plant and Soil, 332, 299-318

Çakmakçı R, Ertürk Y, Dönmez MF, Erat M, Haznedar A, Sekban R 2012. Tea growth and yield in relation to mixed cultures of $\mathrm{N}_{2}$ fixing and phosphate solubilizing bacteria. The Journal of Ege University Faculty of Agriculture, 1, 17-21

Çakmakçı R, Ertürk Y, Varmazyari A, Atasever A, Kotan R, Haliloğlu K, Erat M, Türkyılmaz K, Sekban R, Haznedar A 2017. The effect of bacteria-based formulations on tea (Camellia sinensis L.) growth, yield, and enzyme activities. Annals of Warsaw University of Life Sciences - SGGW Horticulture and Landscape Architecture No 38, 5-18 Ann. Warsaw Univ. of Life Sci. - SGGW, Horticult. Landsc. Architect. 38, 2017.

Cakmakçı R 2019. The Variability of the Predominant Culturable Plant GrowthPromoting Rhizobacterial Diversity in the Acidic Tea Rhizosphere Soils in the Eastern Black Sea Region. Alinteri J. of Agr. Sci. 34(2): 175-181

Dutta J, Handique PJ, Thakur D 2015. Assessment of Culturable Tea Rhizobacteria Isolated from Tea Estates of Assam, India for Growth Promotion in Commercial Tea Cultivars. Front. Microbiol. , https://doi.org/10.3389/fmicb.2015.01252.

Ertürk Y, Ercişli S, Sekban R, Haznedar A, Dönmez MF 2008. The effect of Plant Growth Promoting Rhizobacteria (PGPR) on rooting and root growth of tea (Camellia sinensis var. Sinensis) cuttings. Romanian Biotechnological Letters., V. 13, N: 3. p:3747-3756

Ertürk Y, Çakmakçı R, Dönmez MF, Sekban R, Haznedar A 2010a. Farklı çay klonlarında biyolojik gübrelemenin kullanım olanakları. IV. Organik Tarım Sempozyumu 28 Haziran-01 Temmuz 2010, Erzurum (1), 777-782.

Ertürk Y, Ercişli S, Haznedar A, Çakmakçı R 2010b. Effects of plant growth promoting rhizobacteria (PGPR) on rooting and root growth of kiwifruit (Actinidia deliciosa) stem cuttings. Biol Res, 43: 91-98.

Ertürk Y, Çakmakçı R, Dönmez MF, Sekban R, Haznedar A 2011a. Fener-3 Çay klonu fidanlarında enjeksiyon ve daldırma metotları ile PGPR uygulamalarının verim üzerine etkilerinin incelenmesi. GAP IV. Tarım Kongresi 9-12 Mayıs 2011, Şanlıurfa, s:29-34.

Ertürk Y, Çakmakçı R, Duyar Ö, Turan M 2011b. The effects of plant growth promotion rhizobacteria (PGPR) on vegetative growth and leaf nutrient contents of hazelnut seedlings (Turkish hazelnut cv, Tombul and Sivri). International Journal of Soil Science 6(3):188-198

Ertürk Y, Çakmakçı R, Dönmez MF, Sekban R, Haznedar A 2011c. Doğu Karadeniz Bölgesi Asidik Topraklarından İzole edilmiş Bazı Bitki Büyümesini Teşvik Edici Rizobakterilerin (PGPR) Çay Bitkisinin Fidan Gelişimi Aşamasında Kullanım Olanaklarının Araştırılması. Türkiye VI. Ulusal Bahçe Bitkileri Kongresi 4-8 Ekim 2011, Şanlıurfa, Cilt 1: Meyvecilik, s:202-211.

Ertürk, Y, Ercişli S, Çakmakçı R 2012. Yield and growth response of strawberry (FragariaX ananassa Duch.) to plant growth promoting Rhizobacteria inoculation. Journal of Plant Nutrition (35:817-826).

Ertürk Y, Çakmakçı R, Sekban R, Haznedar A 2013. Çay yetiştiriciliğinde bitki büyümesini teşvik edici bakteri uygulamaları alternatif olabilir mi ? Türkiye V. Organik Tarım Sempozyumu 25-27 Eylül 2013. Samsun, cilt 1, s:4751.

Ertürk Y, Çakmakçı R, Sekban R, Haznedar A 2014. Biological Fertilizer Researches For Organic Tea Culture in Turkey (Period: 2007- 2013). Abst. International Mesopotamia Agriculture Congress / 22-25 September 2014 Diyarbakır - Turkey, s 1004-1005.

Fauziah F, Setiawati MR, Pranoto E, Susilawati DN, Rachmiati Y 2019. Effect of indigenous microbes on growth and blister blight disease of tea plant. J. of Plant Protection Research 53(4):529-534. doi:10.24425/jppr.2019.131264.

Gebrewold AZ 2018. Review on integrated nutrient management of tea (Camellia sinensis L.). Cogent Food \& Agriculture, 4: 1543536 https://doi.org/10.1080/23311932.2018.1543536 
Glick BR 1995. The Enhancement of Plant Growth by Free Living Bacteria. Canadian Journal of Microbiology, 41,109117. http://dx.doi.org/10.1139/m95-015

Glick BR, Cheng Z, Czarny J, Duan J 2007. Promotion of plant growth by ACC deaminase-producing soil bacteria. Eur. J. Plant Pathol. 119, 329-339. https://doi.org/10.1007/s10658-007-9162-4.

Gulati A, Sood S, Rahi P, Thakur R, Chauhan S, Chadha IC 2011. Diversity analysis of diazotrophic bacteria associated with the roots of tea (Camellia sinensis (L.) O. Kuntze) J. Microbial. Biotechnol. 21(6):545-555. doi:10.4014/jmb.1012.12022.

Islam S, Hamid FS, Ahmad F, Waheed A, Shah BH, Aslam S, Hussain S 2015. Impact of different fertilizer mixtures on growth performance of tea cuttings. Journal of Agricultural Research (03681157), 53(2).

Islam S, Hamid FS, Amin K, Sumreen S, Q.uz-Zamane K, N. Khan A, Hussain BS 2017. Effect of Organic Fertilizer on the Growth of Tea (Camellia sinensis L.). International Journal of Sciences: Basic and Applied Research (IJSBAR) Volume 36, No 8, pp 1-9.

Jianyun R, Lifeng MA, Xiaoyun Y, Yuanzhi SH, Kang N, Meiya L, Qunfeng Z 2020. Integrated Nutrient Management in Tea Plantation to Reduce Chemical Fertilizer and Increase Nutrient Use Efficiency. Journal of Tea Science 40 ( 1):85-95.

Kacar B 2010. Çay Bitkisi biyokimyası, gübrelenmesi, işlenme teknolojisi, Nobel Yayın No: 1549, Fen Bilimleri: 107, ISBN 978-605-395-359-3.

Kloepper JW 1994. Plant growth promoting bacteria (other systems). Azospirillum/plant association. Edited by Okon, J., Boca Raton, Fl: CRC Press, 137-154.

Nepolean P, Jayanthi R, Pallavi V, Balamurugan A, Kuberan T, Beulah T, Premakumar R 2021. Role of biofertilizers in increasing tea productivity. Asian Pac. J. Trop. Biomed., 1443-S1445.

Pırlak, L, Turan M, Şahin F, Eşitken A 2007. Floral and foliar application of plant growth promoting rhizobacteria (PGPR) to apples increases yield, growth and nutrient element contents of leaves. Journal of Sustainable Agriculture, $30,145-155$.

Phukan I, Madhab M, Sarmah SR, Bordoloi M, Nair SC, Dutta P, Begum A, Tanti S, Bora SC, Nair S, Rai S, Debnath and Barthakuret BK 2012. Exploitation of PGP microbes of tea for improvement of plant growth and pest suppression: A novel approach, Two Bud 59(1):69-74.

Princy T, Kumar R, Radhakrishnan B, Marecswaran J, Jayanti R, Nepoloean P 2015. Role of indigeneous PGPR in integrated nutrient management of growth and development in tea nursery. Int. J. F Current Res. 7(8):19821-19825.

Shang J, Liu B 2020. Application of a microbial consortium improves the growth of Camellia sinensis and influences the indigenous rhizosphere bacterial communities. J Appl Microbiol Online ahead of print https://doi.org/10.1111 /jam.14927.

Sharangi AB 2009. Medicinal and therapeutic potentialities of tea (Camellia sinensis L.) - A review Food Research International 42:529-535.

Sudhakar P, Chattopadhyay GN, Gangwar SK, Ghosh JK 2000. Effect of foliar application of Azotobacter, Azospirillum and Beijerinckia on leaf yield and quality of mulberry (Morus alba). J. Agr. Sci, 134, 227-234.

Tennakoon PLK, Rajapksha RMCP, Hettrachchi LSK 2019. Tea yield maintaned in PGPR inoculated field plants despite significant reduction fertilizer application. Rhizosphere 10:100-146.

Wang M, Sun H, Xu L, Xu Z 2020. Bacterial diversity in tea plant (Camellia sinensis) rhizosphere soil from Qinling Mountains and relationship with environmental elements. Plant Soil. https://doi.org/10.1007/s11104-020-04822-8.

Wanyoko JK, Othieno CO, Mwakha E, Cheruiyot DK 1997. Effects of types and rates of nitrogen fertilizer on leaf nutrient contents of seedling tea in Nmandi hills, Kenya. Tea, 18 (1): 21 - 31.

Verma DP 1997. Balanced fertilization for sustainable productivity of tea. Fertilizer News. 42(4): 113-125. 